\title{
Reestruturação Produtiva e Transformações no Emprego Industrial frente ao Avanço da Silvicultura do Eucalipto no Sudoeste Maranhense
}

\author{
Productive Restructuring and Transformations in Industrial Employment in advance \\ the Eucalyptus Forestry Advancement in Southwest Maranhense
}
Reestructuración Productiva y Transformaciones en el Empleo Industrial frente al Avance de la Silvicultura del Eucalipto en el Sudoeste Maranhense

\author{
Allison Bezerra Oliveira ${ }^{1}$ \\ Daniely Lima Silva ${ }^{2}$ \\ Maria da Conceição Mesquita Leal ${ }^{3}$
}

\begin{abstract}
RESUMO: $O$ presente artigo tem por objetivo apresentar o processo recente de reestruturação produtiva pelo qual o sudoeste maranhense vem passando a partir da implantação da unidade fabril da Suzano Papel e Celulose no município de Imperatriz, bem como o consequente avanço da silvicultura do eucalipto como elemento motriz da cadeia produtiva dessa indústria. No centro de tais transformações, busca-se compreender as mudanças recentes no emprego industrial local, analisando os processos de requalificação profissional ordenados pela empresa e agentes locais para atender à estrutura econômica em curso e seu processo de especialização. A construção da base analítica de dados aqui apresentados considerou a produção cartográfica de áreas de avanço da silvicultura do eucalipto no Maranhão, os registros de instituições de formação em nível médio/técnico e superior da cidade-sede da indústria e dados do Instituto Brasileiro de Geografia e Estatística IBGE (2017), do Instituto Brasileiro de Árvores (2017), da Relação Anual de Informações Sociais RAIS (2018) e do Cadastro Geral de Empregados e Desempregados (2018). Os resultados obtidos sugerem que há em curso um processo de requalificação na formação do empregado local para atender às demandas da unidade fabril da Suzano no que compete ao fornecimento de força de trabalho.
\end{abstract}

PALAVRAS-CHAVE: Reestruturação produtiva. Emprego industrial. Silvicultura. Sudoeste maranhense.

\footnotetext{
${ }^{1}$ Universidade Estadual da Região Tocantina do Maranhão - UEMASUL. R. Godofredo Viana, 1300 - Centro, Imperatriz - MA, 65900-000. allisonbzr@gmail.com.

${ }^{2}$ Universidade Estadual da Região Tocantina do Maranhão - UEMASUL. R. Godofredo Viana, 1300 - Centro, Imperatriz - MA, 65900-000. daniely.slyma@gmail.com.

${ }^{3}$ Universidade Estadual da Região Tocantina do Maranhão - UEMASUL. R. Godofredo Viana, 1300 - Centro, Imperatriz - MA, 65900-000. mharya.leal@gmail.com.
} 
Reestruturação Produtiva e Transformações no Emprego Industrial frente ao Avanço da Silvicultura...

ABSTRACT: This article goal is to present the recent process of the productive chain restructure in the southeast of the Maranhão State that started right after the implementation of the paper and cellulose plant Suzano in the city of Imperatriz, with the use of eucalyptus as main element of the productive chain in this type of industry. We try to understand, based on these changes, how the labor local market has changed, analyzing the process of requalification of professionals based in the requirements of the company and its local agents in order to fulfill the new economical process with the required specialization level. In order to achieve this goal was utilized an analytical data with the following information: geographical production and increase of eucalyptus plantation in the Maranhão state, also the graduation records of high school, technical school and bachelor's degree where the plant is located, and data provided by Instituto Brasileiro de Geografia e Estatística - IBGE, Yearly relation of Social Information - RAIS and General subscription of employment and unemployment CAGED. The results suggest that there's a change in how the local economy is changing to attend the demands of the plant Suzano in all the competences required to provide effective professionals.

KEYWORDS: Productive restructuring. Industrial employment. Silviculture. Southwest maranhense.

RESUMEN: Este artículo tiene como objetivo presentar el reciente proceso de restructuración productiva del suroeste maranhense a partir de la implementación de la unidad fabril Suzano Papel y Celulosa en el municipio de Imperatriz, así como el consecuente avance de la silvicultura del eucalipto como elemento motriz de la cadena productiva de esta industria. En el centro de tales transformaciones, se busca comprender los cambios recientes relacionados a los empleos en la industria local, analizando los procesos de recalificación profesional coordinado por la empresa y agentes locales para atender a la estructura economía actual y sus procesos de especialización. La construcción de la base analítica de datos de la producción cartográfica consideró la de áreas de avance de la silvicultura del eucalipto en el estado de Maranhão, los registros del Instituto de Formación en Nivel Medio/Técnico y Superior de la ciudad-sede de la industria, los datos del Instituto Brasileiro de Geografia e Estatística - IBGE (2018), también de la Relación Anual de informaciones Sociales - RAIS (2018) y del Catastro General de Empleados y Desempleados - CAGED (2018). Los resultados obtenidos sugieren que hay en curso un proceso de recalificación en la formación del empleado local para atender a las demandas de la unidad fabril de Suzano en que compete al fornecimiento de fuerza de trabajo.

PALABRAS-CLAVE: Reestructuración productiva. Empleo industrial. Silvicultura. Suroeste maranhense.

\section{INTRODUÇÃO}

No capitalismo, o crescimento econômico é, como Harvey (2013) destaca, um processo de contradições internas, que, frequentemente, passa por crises. Desta forma, nesse sistema, o crescimento harmonioso ou equilibrado é, para o autor, assim como para Marx (1985), inteiramente acidental, devido à natureza espontânea e caótica da produção de mercadorias sob o capitalismo competitivo. Como exemplo de crises que reformulam os processos de contradições próprios do capitalismo, citam-se as ocorridas no modelo fordista/taylorista de produção. Tais crises são próprias da gênese do capital e se reorganizam sempre em ciclos que desembocam ao final em novos processos de reestruturação da produção e da força de trabalho. 
Em especial, a crise no modelo fordista/taylorista desencadeou, sobretudo em meados do século $\mathrm{XX}$, a necessidade de novos modelos concorrenciais e de acúmulo de capital nas atividades industriais em um regime neoliberal de concorrência cada vez mais global. Tal circunstância impulsionou uma expressiva reestruturação produtiva do setor secundário mundial, orientado pela busca de máxima otimização dos agentes econômicos, dos lucros e da velocidade de produção.

Ao tal processo de reconfiguração segue uma intensa estratégia geográfica de acumulação flexível. Nos termos propostos por Harvey $(2008,2011,2013)$, isso implica a flexibilização da produção através da desconcentração das unidades fabris, o aproveitamento cada vez maior de recursos espaciais como terra e água, além da própria flexibilização da força de trabalho. No Brasil, esse processo foi impulsionado pela atuação do Estado, acentuou-se a partir da década de 1970 (sobretudo nesse período), acompanhando transformações dos avanços neoliberais no mundo, liderados por Ronald Reagan nos Estados Unidos e Margaret Thatcher no Reino Unido (CANO, 1986; LEITE, 1997; SUZIGAN, 2000).

Mais do que desconcentração da atividade industrial, pensar tais processos de reestruturação implica compreender que tais atores hegemônicos, ao se instalarem em regiões periféricas, tendem a emitir suas próprias orientações para ordenamento do território e a implantar de forma eficaz suas especializações e lógica produtiva. Em outras palavras, nas localidades escolhidas, os sistemas de objetos e de ações, e o espaço como um todo, são chamados a colaborar com os processos econômicos em voga em meio a um discurso eficaz sobre desenvolvimento e criação de empregos diretos e indiretos (SANTOS, 2008; SANTOS; SILVEIRA, 2001).

A respeito desse processo, especificamente no sudoeste maranhense, observa-se que houve um discurso de "modernização" da Amazônia legal, acompanhado de uma contrapartida dos governos federal, estadual e municipais, materializada na forma de incentivos fiscais, doações de terra, construções de estradas, portos, ferrovias, hidrelétricas e outras estruturas visando atrair o grande capital para a região (D'INCAO; SILVEIRA, 1994; OLIVEIRA; PEREIRA; NASCIMENTO, 2018; PANTOJA; PEREIRA, 2016; SANT'ANA JÚNIOR, 2014).

Em específico, é possível pensar o desenvolvimento da cadeia produtiva de papel e celulose que se insere nesses modelos históricos de reconfiguração produtiva e instalação industrial. Assim, a partir das transformações concorrenciais que perpassaram a indústria desse segmento no Brasil e no mundo e daquilo que Santos e Silveira (2001) destacam como a guerra fiscal dos lugares, a empresa Suzano Papel e Celulose anunciou, em 2007, seu plano de expansão com a construção de duas plantas industriais, sendo uma localizada no município de Imperatriz, no estado do Maranhão. 
Reestruturação Produtiva e Transformações no Emprego Industrial frente ao Avanço da Silvicultura...

A cadeia produtiva de papel e celulose abrange as etapas de produção de madeira, energia, celulose e papel, reciclagem de papel, produção gráfica e editorial e também atividades de comércio, distribuição e transporte. Esse segmento necessita essencialmente de espaços com grande potencial hidrológico e terra a preços baixos que permitam o plantio e a colheita de eucalipto e, sobretudo, mão de obra em grande quantidade.

Nesse processo, o espaço geográfico representa um suporte essencial, além de ser a base material dos processos produtivos. É visto pela atividade industrial a partir de aspectos estratégicos, passando, assim, a ser transformado para atender às etapas dos processos fabris: extração, produção, circulação e consumo. Logo, o espaço traduzido pelas perspectivas de localização das atividades constitui elemento que se generaliza como estratégia fundamental para a (re)produção dos sistemas econômicos e da própria acumulação, desencadeando, dessa forma, uma multiplicidade de transformações e expressivos impactos.

Desse modo, dois elementos são fundamentais no processo de reestruturação produtiva pelo qual o sudoeste do Maranhão tem passado com o avanço da silvicultura da celulose: a expansão de áreas destinadas para essa cultura e a requalificação de força de trabalho local para atender à demanda de novos empregos fundamentais em tal cadeia. $O$ município de Imperatriz e sua microrregião estão inseridos no sudoeste maranhense e têm historicamente sua economia baseada nos setores primário e terciário. Recentemente, a partir da implantação da unidade fabril, objeto desta pesquisa, tem passado por expressivos processos de transformação, sendo levado a uma especialização produtiva fundamentada na cadeia de papel e celulose.

No bojo das transformações e impactos, o presente trabalho visa apresentar e discutir algumas das principais alterações no mercado de trabalho e na formação profissional, desencadeadas pela implantação da unidade fabril da Suzano em Imperatriz, compreendendo assim a requalificação da força de trabalho não apenas como instrumento fundamental de uma nova estrutura proposta, mas também como elemento sujeito pura e meramente às dinâmicas dos grupos hegemônicos e do interesse corporativo em voga.

A construção da base analítica de dados aqui apresentados considerou, além de produção cartográfica de áreas de avanço da silvicultura do eucalipto e sua dinâmica produtiva no estado do Maranhão, também os registros de instituições de formação em nível médio/técnico e superior da cidade-sede da indústria para fins de compreensão das transformações nas ofertas de e na procura por cursos de capacitação técnica e de formação superior, e, por fim, informações colhidas na base de dados do IBGE (2017), do (IBÁ) Instituto Brasileiro de Árvores (2017), da (RAIS) Relação Anual de Informações Sociais (2018), (CAGED) Cadastro Geral de Empregados e Desempregados (2018), Censo da Educação superior do município de Imperatriz no (INEP) Instituto Nacional de Estudos e 
Pesquisas Educacionais Anísio Teixeira (2017) e do (PDET) Programa de Disseminação das Estatísticas do Trabalho (2018) sobre as mudanças na estrutura ocupacional e profissionalizante desencadeadas pelo processo de reestruturação produtiva em curso.

A organização do trabalho, além desta introdução e das considerações finais, apresenta-se da seguinte forma: inicialmente, em "A indústria de papel e celulose e sua cadeia produtiva", traça-se uma breve narrativa do processo de evolução da indústria de papel e celulose no Brasil e o detalhamento de sua cadeia produtiva; em seguida, em "A implantação da Suzano Papel e Celulose em Imperatriz e o avanço da silvicultura do eucalipto no Maranhão", apresenta-se o processo recente de implantação da unidade fabril da Suzano na cidade de Imperatriz, no estado do Maranhão, e o processo de reestruturação produtiva e consequente especialização do território devido ao avanço das áreas destinadas ao cultivo da silvicultura do eucalipto; e, por fim, em "Qualificação e alterações no perfil profissional frente ao avanço da cadeia produtiva de papel e celulose no sudoeste maranhense", discute-se a partir de dados secundários as alterações expressivas no mercado de trabalho local frente às transformações econômicas aqui discutidas.

\section{A INDÚSTRIA DE PAPEL E CELULOSE E SUA CADEIA PRODUTIVA}

Um marco fundador da confecção de papel com materiais celulósicos é registrado em 1770, no Rio de Janeiro, através de uma publicação onde se expunham espécies vegetais que poderiam ser utilizadas na produção de papel. Apesar disso, a instalação das indústrias só começa a ocorrer em 1830, tornando-se mais evidente em 1920, mediante os incentivos fiscais do governo, o que fortaleceu o incremento de mais indústrias. A produção inicial era diretamente vinculada à demanda da Companhia Paulista de Estradas de Ferro, entretanto, após 1966 - por meio da Lei № 5.106 de 02/09/1966 - foram disponibilizados incentivos fiscais para a atividade de reflorestamento, gerando um aumento de plantios de 500 mil para três milhões de hectares (LEÃO, 2000; SUZIGAN, 2000).

Mesmo assim o país ainda importava não só todo o papel que consumia, mas também a pasta de madeira utilizada na produção interna de papel. Sobre esse contexto, Suzigan (2000) explica que foram buscadas fontes alternativas para produção de celulose através da empresa Companhia Melhoramentos de São Paulo, considerada a primeira fábrica de papel instalada em São Paulo em 1883. Esta passou a investir em pesquisas de espécies de vegetais nativos do país, com supervisão de engenheiros agrônomos e florestais contratados na Europa. É importante frisar que durante muito tempo o Brasil foi fortemente dependente dos Estados Unidos para o fornecimento de papel, mesmo tendo condições ambientais para a produção em grande quantidade. 
Reestruturação Produtiva e Transformações no Emprego Industrial frente ao Avanço da Silvicultura...

Além dessa empresa, a Klabin, Irmão \& Companhia foi fundada em São Paulo em 1910. Sendo a primeira a possuir máquinas para produção de pasta de madeira, essa empresa logo alcançou a posição de maior indústria de papel e celulose no Brasil, em 1940. Contudo, nos primeiros anos da guerra, a indústria de papel sofreu grandes baixas pela escassez de matéria-prima para sua fabricação, fazendo com que se utilizassem trapos, papel velho e palha de arroz, ou seja, itens recicláveis como alternativa para produção, sem esquecer também a falta de proteção tarifária, assim como as dificuldades de logística: acesso a transporte e matéria-prima. Além disso, as indústrias produziam apenas papel de embrulho e papelão nas tonalidades marrom ou cinza, considerado uma produção grosseira, logo, não havia uma perspectiva de progresso para essa indústria, já que ela não conseguia produzir produtos com qualidade superior.

Anos depois, com tarifas concedidas pelo governo, estabeleceram-se duas novas fábricas no Brasil: a Papel Pernambucana Skitieselskab, em Pernambuco, no ano de 1916, e a Paraná PaperCompany, no Paraná, em 1917. Ambas eram providas de investimentos de capitais estrangeiros, que passaram a ser cada vez mais presentes no Brasil, principalmente na década de 1920; entre 1925 e 1927 o número de fábricas de papel passou de 15 para 23 (SUZIGAN, 2000). Uma consequência desse aumento foi uma produção que excedeu a demanda, provocando a queda do preço do papel. Além disso, outro problema grave era a falta de pasta de madeira e celulose para alimentar a indústria.

Nesse contexto de crise, o governo entrou mais uma vez como salvador, incentivando a produção de celulose com a isenção de impostos de importação sobre máquinas e afins para empresas com a finalidade de produzir celulose. No país, até 1930, só havia informações de quatro fábricas de pasta que utilizavam pinho, bambu, papel velho e fibras nativas como matéria-prima; o ponto de virada foi a descoberta do eucalipto como uma alternativa rentável, através de pesquisas de laboratório. Assim, percebe-se que o crescimento da indústria de papel e celulose no Brasil dependeu diretamente dos incentivos públicos, principalmente por meio de parcerias público-privadas, focadas no aprimoramento das culturas de eucalipto originário da Austrália. Pronto para produzir em apenas sete anos, o eucalipto se tornaria ao longo dos anos a principal matéria-prima de produção da cadeia de papel e celulose brasileira.

Em suma, a indústria brasileira de celulose compõe-se das empresas que produzem celulose e pasta de alto rendimento. Essa polpa pode ser vendida nos mercados doméstico e externo (sendo chamada de celulose de mercado) ou ser usada na produção de papel pela própria empresa que a produz (nesse caso, a polpa é chamada de celulose de integração). Já a indústria de papéis compreende as empresas produtoras de papéis assim classificados: papéis de imprensa, de imprimir e escrever, de embalagem, sanitários e cartão, entre outros. 
É importante frisar que a cadeia produtiva industrial é composta por etapas consecutivas de transformação de diversos insumos até chegar ao produto final. Além dos insumos básicos, inclui a matéria-prima, máquinas e equipamentos, distribuição, prestadores de serviços, até chegar aos consumidores. Dessa forma, a indústria de papel e celulose inicia seu processo de produção no plantio do eucalipto, seguido da colheita, na etapa de extração florestal.

Denomina-se setor de celulose e papel o conjunto formado pelas seguintes indústrias: de celulose, de papéis e de artefatos de papéis. Essas três indústrias em conjunto e mais as florestas, a indústria de editoração e gráfica e ainda os segmentos distribuidores vinculados àquelas indústrias constituem a cadeia produtiva da celulose e papel, esquematizada na Figura 1.

Figura 1 - Cadeia produtiva de papel e celulose no Maranhão

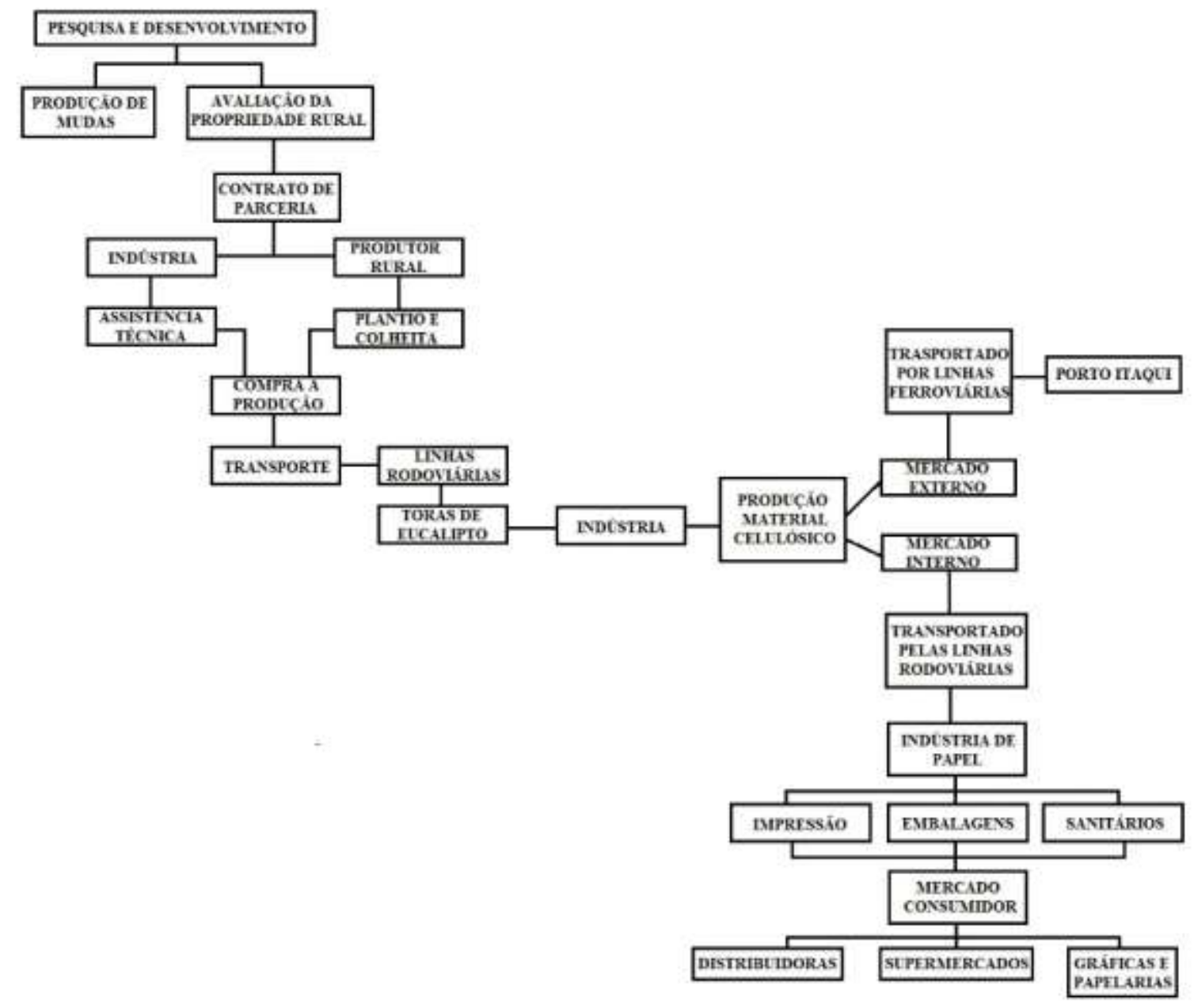

Fonte: Oliveira (2018).

Tal cadeia abrange as etapas de produção de madeira, energia, celulose e papel, reciclagem de papel, produção gráfica e editorial e também atividades de comércio, distribuição e transporte. Esse segmento necessita essencialmente de espaços com grande 
Reestruturação Produtiva e Transformações no Emprego Industrial frente ao Avanço da Silvicultura...

potencial hidrológico, que permitam o plantio e a colheita de eucalipto, além de infraestrutura e localização geográfica estratégica para o escoamento da produção, construção de fábrica e moradia de funcionários (sobretudo aqueles de maior grau de instrução tecnológica ou ocupantes de posições de responsabilidade, como cargos de gestão ou diretamente ligados à Pesquisa, Desenvolvimento e Inovação - PD\&l).

Podemos dividir o esquema apresentado na figura 1 em três partes: a primeira trata da $P \& D$, que é voltada quase que essencialmente para a etapa do plantio e desenvolvimento de novas mudas, mais resistentes e que estejam em condições de serem produzidas em menos tempo. A segunda parte trata da colheita e do transporte; nela a cadeia tem um alto valor agregado mediante a inserção de maquinário para corte, lixamento e retirada, além de caminhões para transporte e todas as empresas fornecedoras de peças e equipamentos. $\mathrm{Na}$ terceira, têm-se as derivações dos vários tipos de papeis produzidos e as várias empresas envolvidas; é a parte da cadeia produtiva que mais possui diversidade dos elementos na produção, pela variedade de produtos oriundos da pasta e do próprio papel.

Esses papéis são vendidos no mercado externo ou no mercado interno, sendo que parte destes últimos se destina à indústria de artefatos de papéis (nas quais se inserem os fabricantes de embalagens de papéis e de outros artefatos de papéis) ou à indústria de editoração e gráfica. Vale destacar que algumas empresas líderes são totalmente verticalizadas (desde a etapa de reflorestamento até a de fabricação de papéis e de artefatos de papéis) e as empresas de pequena escala de operação compram a celulose no mercado para produzir papéis ou compram papéis para produzir artefatos de papéis. As empresas integradas para trás e para frente contam com as vantagens competitivas na produção de celulose, a qual é proveniente no Brasil, em maior parte, da madeira do eucalipto (MONTEBELLO, 2010, p. 14).

No Maranhão, o transporte do papel e pasta de celulose destinado ao comércio interno é feito através do modal rodoviário. Já o transporte para o mercado externo é feito pelo modal ferroviário, que se inicia na cidade de Imperatriz, faz conexão com o terminal Pequiá, na cidade de Açailândia, e segue até o Porto do Itaqui.

\section{A IMPLANTAÇÃO DA SUZANO PAPEL E CELULOSE EM IMPERATRIZ E O AVANÇO DA SILVICULTURA DO EUCALIPTO NO MARANHÃO}

A indústria de papel e celulose, como afirma Leite (1997), passou por um processo, mesmo que tardio, de reestruturação devido às novas demandas concorrenciais e de acumulação econômica global. Nessa lógica, buscou-se, além da inserção de novas tecnologias, a inserção de mão de obra com maior nível de qualificação, a realização de fusões e a localização de espaços geográficos que tivessem capacidade suficiente de 
produzir matéria-prima essencial para a produção industrial, além de incentivos fiscais e posição estratégica que facilitasse o escoamento dessa produção.

Dentro dessa lógica de reconfiguração, as indústrias, para produzirem modernamente, convocam outros atores a participarem de suas ações. O Estado, subordinado à atividade industrial em um novo modelo de guerras fiscais, oferece isenções à custa da exploração do espaço e do discurso de desenvolvimento e criação de empregos diretos e indiretos. $\mathrm{O}$ espaço de atração fica, assim, subserviente à lógica de produção e passa a ser reorganizado a partir de uma dinâmica própria que atenda à empresa.

Em 2008, a empresa Pöyry deu início à implantação da sede da Suzano Papel e Celulose no município de Imperatriz, no estado do Maranhão, com a proposta de ser a maior planta industrial desse segmento no país. A duração da implantação inicial perdurou até o ano de 2013, quando no final do mesmo ano iniciou-se a primeira produção. Além da localização excepcional para o escoamento da produção pelo ramal ferroviário norte-sul até o Porto do Itaqui, outros fatores espaciais também foram importantes no processo: a oferta de serviços urbanos para atender à demanda de mão de obra qualificada que residiria no município, a bacia hidrográfica do Tocantins-Araguaia, além de áreas extensas para o plantio de eucalipto no Maranhão, Tocantins e Pará.

No mapa da figura 2 destaca-se o sudoeste do Maranhão, a localização da fábrica da Suzano Papel e Celulose, em Imperatriz, e a vantagem locacional da implantação de tal fábrica, sobretudo relacionada ao acesso e transporte de matérias-primas e insumos necessários à produção industrial. A bacia do Tocantins-Araguaia, base florestal já existente constituída na década de 1990 (figura 3), os aeroportos, o modal ferroviário da estação Pequiá e sua conexão em direção ao litoral e, consequentemente, o Porto do Itaqui, além das principais linhas rodoviárias, estão no bojo dessa vantagem locacional.

Os transportes no processo de produção e reestruturação assumem papel fundamental na medida em que permitem significativa anulação das distâncias pela viscosidade da locomoção. A capacidade para movimentar os produtos define a mobilidade do capital sob a forma de mercadoria. Essa mobilidade depende das relações de transporte modificadas pelos atributos das mercadorias, como peso, tamanho, fragilidade, mercado consumidor, perecibilidade etc.

Como qualquer outro insumo intermediário, o valor da mercadoria "mudança de localização" entra no preço de custo de outras mercadorias. Por isso, o valor de todas as mercadorias inclui todos os custos socialmente necessários de transporte, definidos como o custo médio de levar os produtos a seus destinos. O custo do movimento não é a única consideração. A regularidade e a confiabilidade dos fluxos do transporte podem reduzir a necessidade de estoques tanto das matérias-primas quanto dos produtos acabados e, portanto, liberar o capital "ocioso" para a acumulação ativa. A continuidade na circulação do capital só pode ser 
assegurada mediante a criação de um sistema de transporte eficiente e espacialmente integrado, organizado em torno de alguma hierarquia dos centros urbanos. A velocidade do movimento também é fundamental. A "distância espacial" então se reduz ao tempo porque "não depende, por exemplo, da distância espacial do mercado, mas da velocidade - do quantum de tempo em que se chega ao mercado". (HARVEY, 2013, p. 550$551)$.

Figura 2 - Contexto regional de implantação da unidade fabril da Suzano no Maranhão

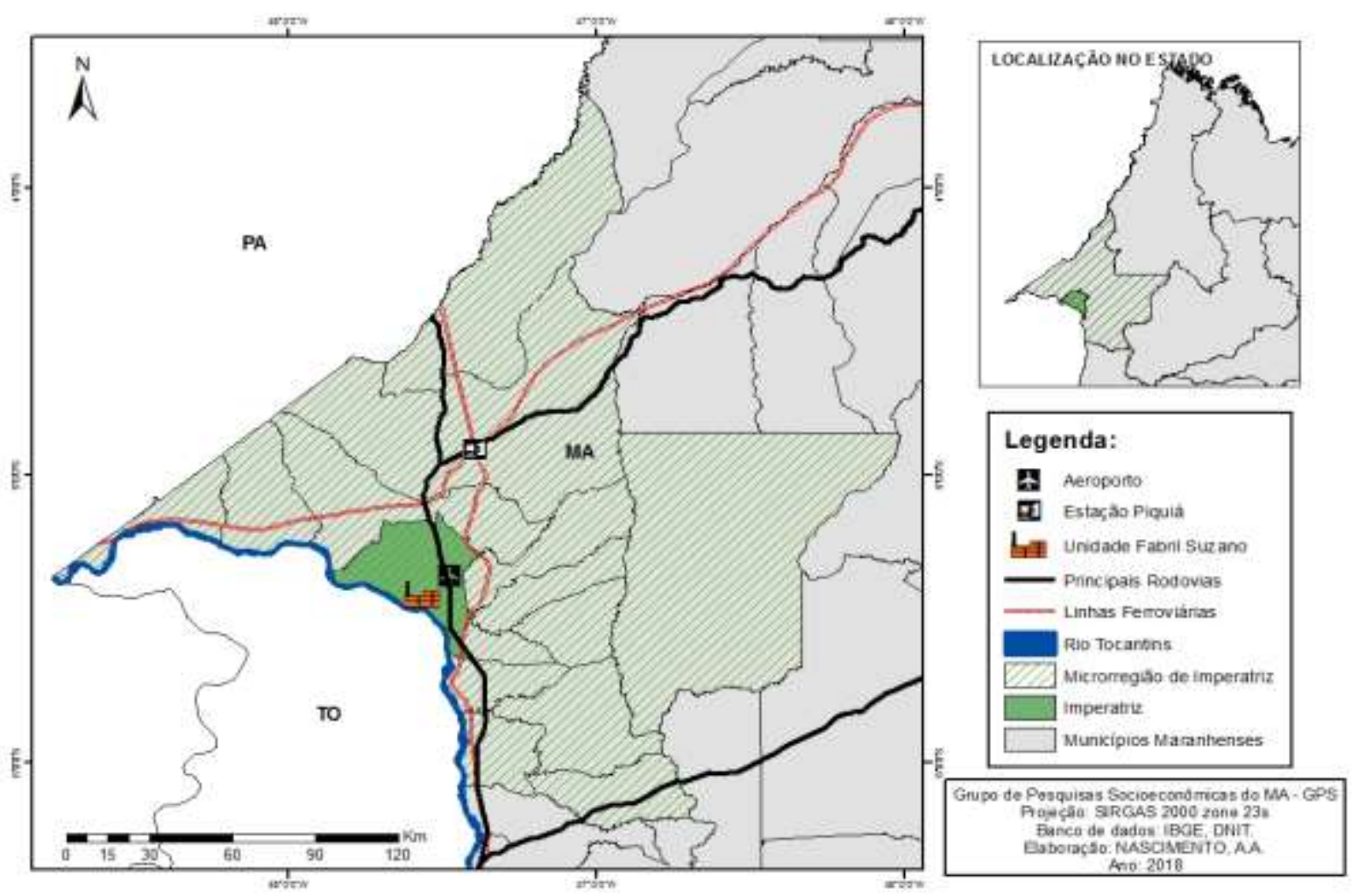

Fonte: dados de pesquisa (2018).

Figura 3 - Áreas de plantio e depósito de cavados da unidade fabril

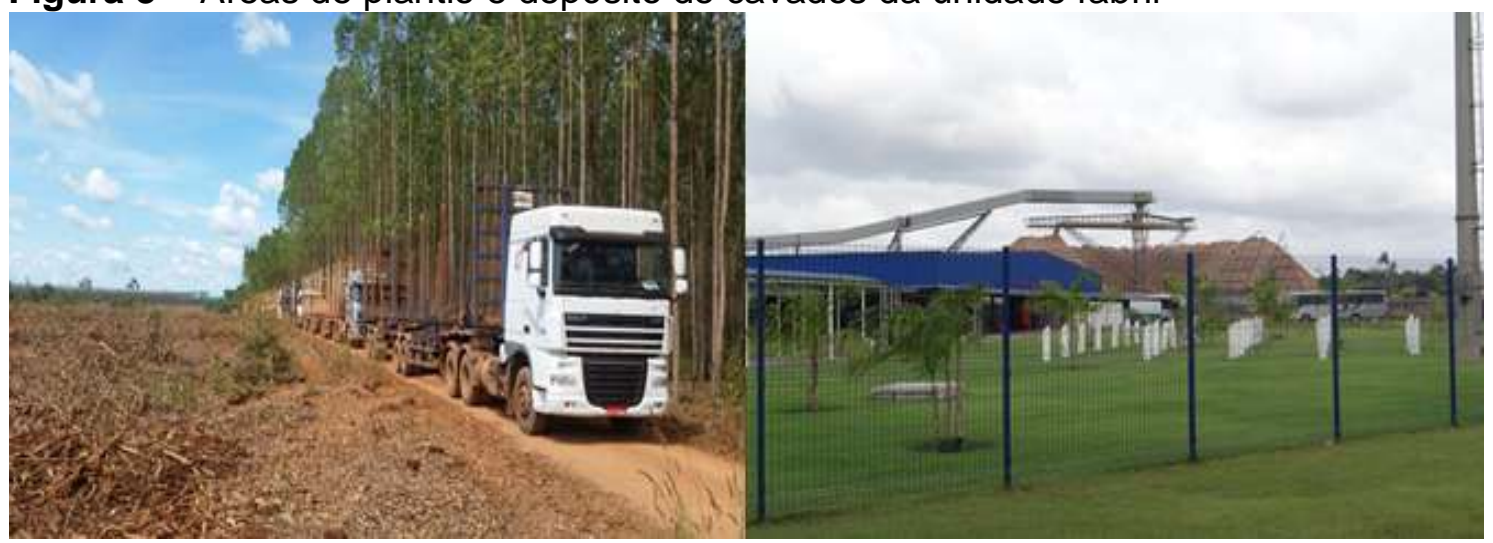

Fonte: dados de pesquisa (2018).

A mobilidade do capital na forma de mercadoria é realizada dentro de uma estrutura em eterna modificação dos espaços relativos, pois o custo e as distâncias de tempo podem ser alterados pelo desenvolvimento dos meios de transporte de uma maneira que não 
corresponda às distâncias geográficas. Na figura 4 percebe-se o avanço da silvicultura como suporte material do fornecimento de matéria-prima para a cadeia produtiva de papel e celulose e a gradativa ubiquidade de matéria-prima - traduzida pelo número de fazendas que contribui não só para a especialização produtiva do território, mas também para a rapidez de produção e consequente reprodução do capital.

Figura 4 - Transporte e avanço de áreas de produção de eucalipto

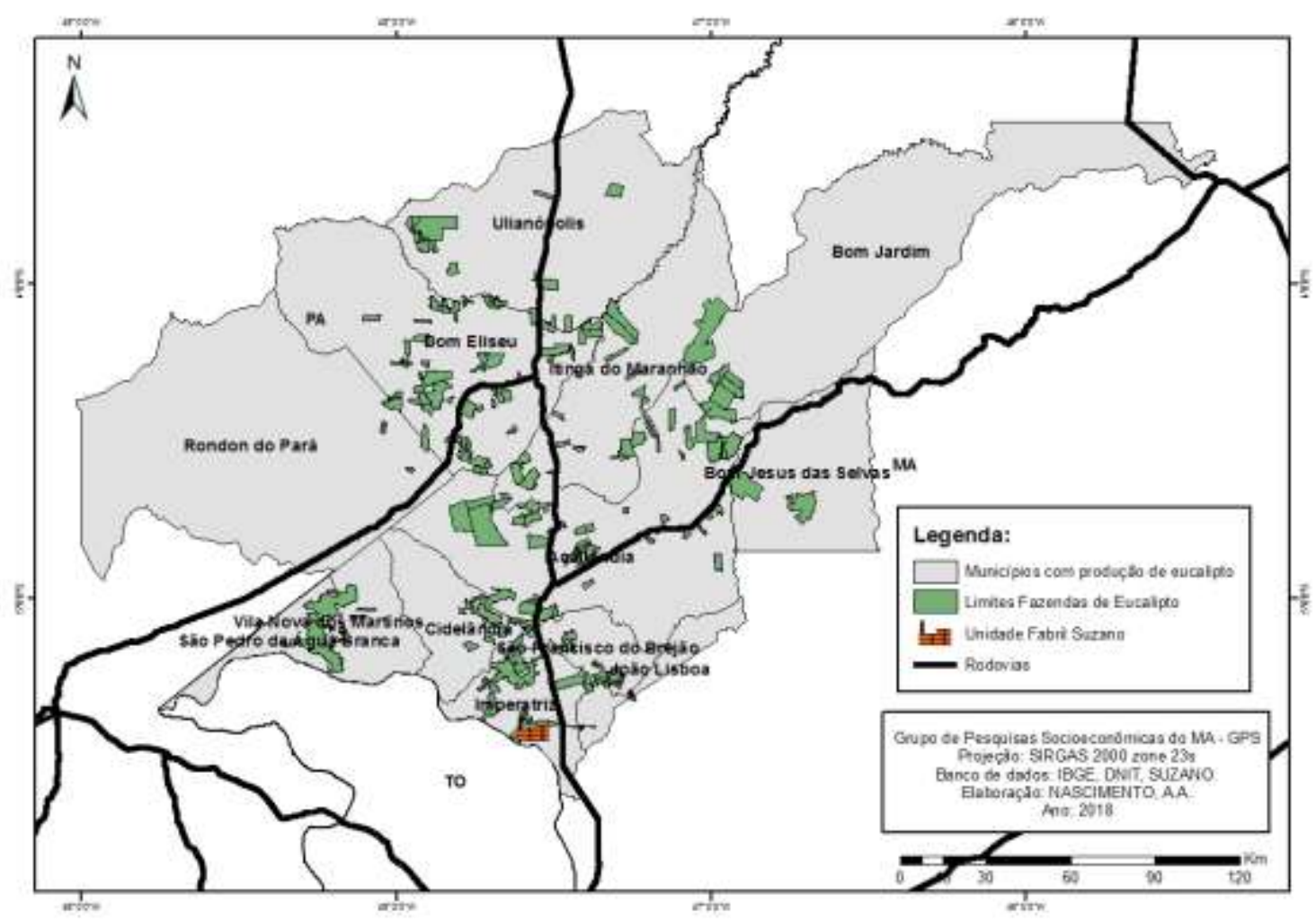

Fonte: dados de pesquisa (2017).

Embora o recorte do mapa apresentado na figura 4 evidencie o avanço das áreas de eucalipto no sudoeste maranhense em meio às rodovias que sustentam o transporte dessa matéria-prima, tal dinâmica pode ser compreendida também como suporte na constituição de uma regionalização para atividades de monocultura destinadas ao grande agronegócio mecanizado; quando se faz o recorte do MAPITOBA, regionalização de parte do Maranhão, Piauí, Tocantins e Bahia, percebe-se o tamanho do projeto de reestruturação em curso. Os detalhes sobre o volume de áreas plantadas podem ser percebidos na figura 5.

Mesmo que a Bahia tenha o maior percentual de áreas destinadas a essa cultura, o Maranhão é o estado com o maior aumento de áreas no período analisado, passando de 151.403 hectares em 2010 para 221.859 hectares em 2016, segundo dados oficiais. Tal modificação do espaço maranhense frente a uma lógica econômica justifica-se também por processos históricos de reestruturação e "integração" de ciclos econômicos no estado. 
Figura 5 - Avanço do eucalipto no MAPITOBA (2010 a 2016)

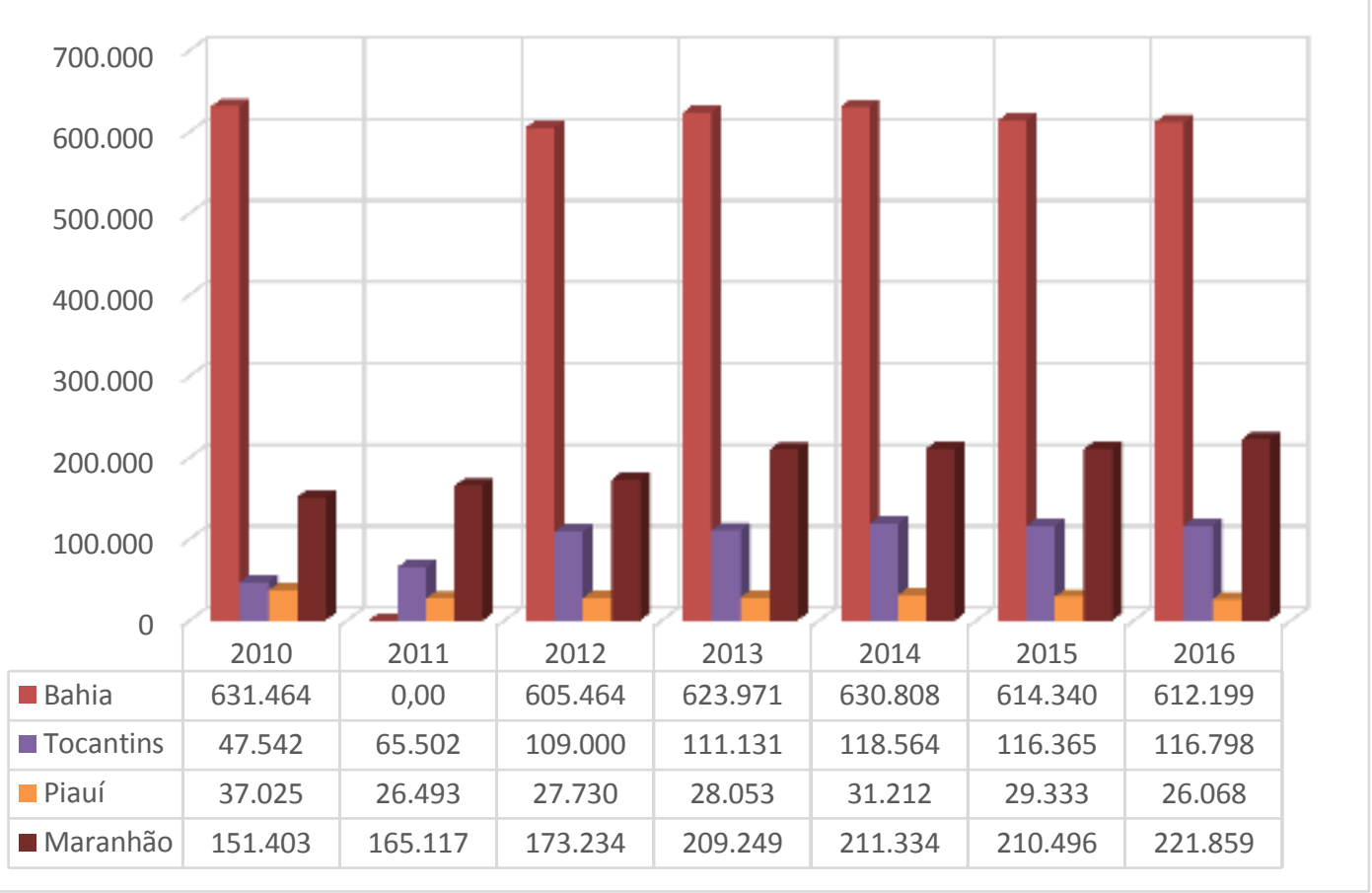

Fonte: Indústria Brasileira de Árvores (2017).

Sobre esse processo e o de "integração" industrial da Amazônia, Pantoja e Pereira (2016), Oliveira, Pereira e Nascimento (2018) percebem que desde a década de 1980, com o Projeto Grande Carajás, já se preparava toda a estrutura para a implementação de novas indústrias na região; é possível observar que desde aquele período a construção da Estrada de Ferro Carajás, que liga a província mineral de Carajás (sudeste do Pará) ao litoral maranhense - o Complexo Portuário de São Luís, formado pelos portos do Itaqui e de Ponta da Madeira - já visava a esse propósito de modelo de expansão industrial.

Tal fato está diretamente ligado à existência da ALUMAR, beneficiadora do mineral extraído, e sua influência no surgimento de oito usinas de processamento de ferro gusa às margens dessa estrada de ferro. Por sua vez, a atividade de processamento de gusa é vinculada à produção de madeira, que foi estimulada pelo projeto CELMAR, em Imperatriz, em 1992. Toda essa estrutura de transporte para o porto e fornecimento de matériaprima sinalizam a própria condição de implementação da Suzano em Imperatriz, cuja presença no estado do Maranhão remonta a meados da década de 1980, quando iniciaram as primeiras experiências no Maranhão com a plantação de eucalipto no leste maranhense, no município de Urbano Santos (OLIVEIRA; PEREIRA; NASCIMENTO, 2018, p. 142).

Além dessa cadeia produtiva mais ampla, construída ao longo das décadas, a questão da localização do empreendimento é algo fundamental para compreender esse processo de implementação industrial no sudoeste maranhense. Isso por que: 
A localização industrial entendida como o lugar ocupado pela indústria no espaço significa um entendimento mais amplo do que a simples pontuação ou endereço das indústrias no mapa. A localização da indústria insere-se no processo da industrialização que determina historicamente, esse lugar a ser ocupado por cada indústria. Do ponto de vista espacial, esse lugar resulta da divisão espacial e internacional do trabalho num dado momento histórico (CARLOS, 1992, p. 20).

A citação possibilita refletir sobre o papel do sudoeste maranhense dentro de uma divisão internacional do trabalho que ultrapassa qualquer observação pautada apenas num endereço industrial na cidade. Por conta disso, é importante considerar a cadeia mais ampla, construída ao longo das décadas anteriores e além dos limites da cidade de Imperatriz. Isso porque a gênese industrial assume duas conotações espaciais intimamente interligadas: a primeira delas é a dinâmica da localização da fábrica, tomando como ponto de partida as possibilidades e perspectivas de rentabilidade. A segunda trata da reorganização do espaço para atender à implantação fabril e suas etapas produtivas: extração, produção, circulação e consumo. E, além disso, para que o processo de reestruturação em curso seja consistente, também se considera a própria qualificação da força de trabalho.

\section{QUALIFICAÇÃO E ALTERAÇÕES NO PERFIL PROFISSIONAL FRENTE AO AVANÇO DA CADEIA PRODUTIVA DE PAPEL E CELULOSE NO SUDOESTE MARANHENSE}

Tradicionalmente, a economia de Imperatriz e sua microrregião - mesmo com a existência de atividades industriais expressivas como no caso da cidade de Estreito (com a indústria sucroalcooleira) e Açailândia (com as siderúrgicas destinadas à produção de ferro gusa) - baseia-se predominantemente nos setores primário e terciário. O setor de serviços é o maior gerador de empregos e tem a maior participação no Produto Interno Bruto - PIB local, o que, historicamente, faz com que haja por parte dos profissionais uma procura por se adequar a determinados perfis em busca de inserção no mercado de trabalho. Comparando os dados da Relação Anual de Informações Sociais (2018) e do Cadastro Geral de Empregados e Desempregados do Ministério do Trabalho e Emprego (2018) em relação aos anos de 2010 e 2015, apresentados na figura 6 é possível observar que o setor terciário foi o setor que apresentou o maior aumento no número de empregos formais; em 2015, foram contabilizados 1.324 empregos a mais que em 2010.

Tal aumento no número de empregos formais registrados pode ser considerado a partir da análise do processo de instalação da Suzano Papel e Celulose no município de Imperatriz, isto pelo fato de que essa atividade econômica - quando da sua implantação -, obrigatoriamente, já carrega consigo um número significativo de prestadores de serviços, 
Reestruturação Produtiva e Transformações no Emprego Industrial frente ao Avanço da Silvicultura...

terceirizados, sem contar a geração de postos de trabalho dessa natureza para atores locais que fazem parte de sua cadeia produtiva. Exclusivamente no setor terciário, houve, segundo a base de dados consultada, saldo de 3.305 empregos a mais em 2015, comparado à contagem anterior, em 2010.

Figura 6 - Participação dos setores econômicos na geração de emprego em Imperatriz

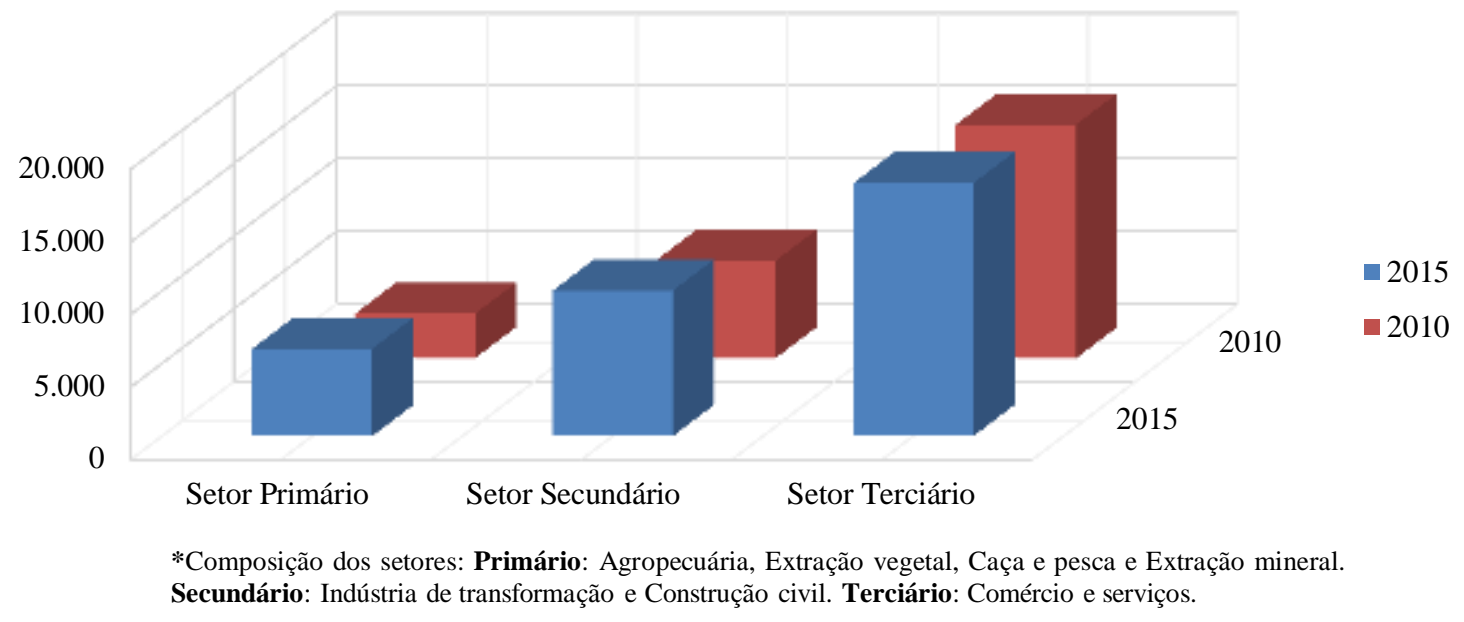

Fonte: Cadastro Geral de Empregados e Desempregados (2018), Programa de Disseminação das Estatísticas do Trabalho (2018) e Relação Anual de Informações Sociais (2018).

O processo de implantação veio acompanhado de profundo apoio estatal por meio de doação de terras, incentivos fiscais e apoio na construção de parcerias para a promoção de cursos de formação em nível médio/técnico e superior para as novas demandas do mercado de trabalho. Boa parte dessas demandas foram preenchidas pela iniciativa privada, principalmente pelas holdings educacionais inseridas na cidade, sobretudo a partir de 2010.

Dessa forma, quando atividades industriais desse porte se instalam no espaço destinado ao processo de produção, elas passam a sobrepor suas próprias técnicas, organizações, conteúdos e formas de produção de trabalho, além de estabelecerem seus próprios mecanismos para suprir a demanda por trabalhadores. Em suma, há um padrão de apropriação espacial do trabalho nos processos de reestruturação produtiva adotados. Com a intensificação da produção, a compreensão de determinada especialização do trabalho passa a ser cooptada e incentivada, como apresentado no quadro 1.

O Quadro 1 apresenta bem as transformações locais quanto à oferta e procura de cursos técnicos para atender às novas necessidades. Há uma clara mudança dos principais cursos ofertados/demandados no período de 2008 a 2010 (anterior ao início das atividades da Suzano) e a partir de 2011 até 2018 (quando a Suzano já havia começado a operar). 
Quadro 1 - Transformações nos principais cursos técnicos ofertados em Imperatriz-MA (2008-2018)

\begin{tabular}{|c|c|}
\hline $\begin{array}{c}\text { Principais cursos técnicos } \\
(2008-2010)\end{array}$ & $\begin{array}{c}\text { Principais cursos técnicos } \\
(2011-2018)\end{array}$ \\
\hline Edificações & Montagem Industrial \\
\hline Laboratório & Operador de Máquinas de Papel \\
\hline Auxiliar Administrativo & Operador de Máquinas Florestais \\
\hline Segurança do Trabalho & Técnico em Automação Industrial \\
\hline Segurança & Técnico em Química \\
\hline Técnico em Informática & Técnico em Operação de Máquinas \\
\hline Eletromecânica & Eletromecânica \\
\hline Eletrotécnica & Eletrotécnica \\
\hline Técnico em Meio Ambiente & Técnico em Meio ambiente \\
\hline Técnico de Celulose e Papel & Técnico de Celulose e Papel \\
\hline
\end{tabular}

Fonte: dados da pesquisa de campo (2018).

Nessa mudança vê-se uma tendência de busca por empregos que insiram a força de trabalho no setor secundário. Cursos como montagem industrial, operador de máquinas de papel, operador de máquinas florestais, técnico em automação industrial, técnico em operação de máquinas e técnico de celulose e papel nunca haviam integrado quadros funcionais na região. Apenas os cursos de eletromecânica, eletrotécnica e técnico em meio ambiente já existiam e permanecem no grupo dos mais ofertados e procurados. $O$ curso de técnico em celulose e papel aparece nos dois momentos, pois é fruto de parceria públicoprivada entre a Suzano e o Instituto Federal de Educação, Ciência e Tecnologia do Maranhão.

No imaginário popular, baseado no discurso do desenvolvimento e da geração de empregos, veem-se nessas mudanças novas oportunidades de trabalho. As instituições de ensino e empresas prestadoras de serviços são convocadas a atender à cadeia produtiva por meio de cursos técnicos, e, além da oferta, há também intensa procura.

Há inevitavelmente uma articulação programada e ao mesmo tempo também involuntária entre empresas, instituições públicas e privadas, além de trabalhadores, de forma a atender sistematicamente à reestruturação local corrente. Tais transformações atingem também as instituições de ensino superior públicas e privadas na medida em que há claro direcionamento das ofertas de novos cursos. Isto porque, os processos de reestruturação produtiva ocorridos no setor secundário mundial necessariamente passaram por transformações diretas na flexibilização do trabalhador.

Assim, para que os processos de reestruturação sejam efetivados, com uma especialização clara do território, são necessárias reorganização, requalificação e reconfiguração da força de trabalho. Tal dinâmica não implica apenas novos modos de 
Reestruturação Produtiva e Transformações no Emprego Industrial frente ao Avanço da Silvicultura...

produção e flexibilização locais, mas, sobretudo a requalificação especializada do trabalhador, que vê nesses processos melhores possibilidades de inserção profissional. Nessa cadeia, as novas tecnologias exigem um trabalhador qualificado, com competências específicas do segmento, conhecimentos básicos e gerais sobre o maquinário e toda a cadeia de produção.

É necessário considerar também as entrelinhas do quadro 2, quando este nos apresenta o perfil do profissional de nível superior desejado, logo, com maior possibilidade de se sobressair profissionalmente. A indústria de papel e celulose e sua extensa cadeia de produção necessitam de expressivo contingente de arquitetos e engenheiros para executar atividades que vão desde desenhos de plantas e construção/manutenção de estruturas civis e mecânicas até o controle e automação de sistemas informatizados industriais e o plantio e manejo das áreas destinadas à silvicultura. Assim, a mudança de perfil profissional aqui discutida também contribui para criar em curto espaço de tempo uma reserva expressiva de mão de obra qualificada com a qual a indústria pode barganhar e contar em casos de crise.

Quadro 2 - Cursos superiores ofertados em instituições de ensino públicas e privadas entre 2011 e 2017

\begin{tabular}{|c|}
\hline Cursos Superiores criados entre 2011 e 2017 \\
\hline Ciência da Computação \\
\hline Engenharia Florestal \\
\hline Engenharia Civil \\
\hline Engenharia de Produção \\
\hline Engenharia Elétrica \\
\hline Engenharia de Produção \\
\hline Engenharia Mecânica \\
\hline Engenharia Elétrica \\
\hline Engenharia Química \\
\hline Arquitetura \\
\hline
\end{tabular}

Fonte: Instituto Nacional de Estudos e Pesquisas Educacionais Anísio Teixeira (2017).

Para Salm et al. (1997), é necessário compreender os vínculos inseridos no contexto global a respeito do trabalho e de todas as formas de qualificação, contexto no qual funções pouco competitivas tendem a ser substituídas por novas funções de maior competitividade e relevância, em um mercado de trabalho global em que setores empregatícios são "excluídos" para que novas áreas possam ser criadas.

Nesse sentido, mais do que uma mera sobreposição entre "o antigo e o moderno", é importante compreender a dinâmica de coexistência entre setores econômicos e atividades que no bojo da competitividade encontram caminhos para impor suas próprias lógicas, 
atraindo trabalhadores e criando sinergias para que estes se qualifiquem e se insiram em seus segmentos.

Há desta forma, o que Alves (1999) classifica como uma interpretação cada vez maior entre funções ou profissões "produtivas" e funções ou profissões ditas "improdutivas". Ocorrendo uma reconfiguração do trabalho industrial no interior da produção do capital. A indústria de papel e celulose e sua cadeia não são únicas nesse quesito, mas exemplificam bem o debate aqui proposto, como podemos ver no quadro 3 , a seguir.

Quadro 3 - Alterações na empregabilidade de Imperatriz (2008 a 2018)

\begin{tabular}{|c|c|}
\hline \multicolumn{2}{|c|}{ Profissões mais exercidas em Imperatriz - MA (2008 a 2018) } \\
\hline 2008 a 2012 & 2013 a 2018 \\
\hline Técnico gráfico & Operador de caldeira \\
\hline Secretária & Operador de calcinação (tratamentos químicos e afins) \\
\hline Recepcionista (geral) & Operador de máquina de fabricar papel e papelão \\
\hline Gerente de produção e operações & Eletricista de manutenção eletroeletrônica \\
\hline $\begin{array}{c}\text { Trabalhador da manutenção de } \\
\text { edificações }\end{array}$ & Engenheiro florestal \\
\hline Apontador de mão de obra & Gerente de projetos e serviços de manutenção \\
\hline Acabador de embalagens & Alimentador de linha de produção \\
\hline Gerente administrativo & Técnico de manutenção elétrica de máquina \\
\hline Administrador & Técnico de celulose e papel \\
\hline Auxiliar de Escritório (geral) & Analista de desenvolvimento de sistemas \\
\hline Operador de guilhotina (corte de papel) & Administrador de sistemas operacionais \\
\hline Operador de computador & Operador de digestor de pasta para fabricação de papel \\
\hline Vendedor & $\begin{array}{c}\text { Cilindreiro na preparação de pasta para fabricação de } \\
\text { papel }\end{array}$ \\
\hline Embalador & Técnico mecânico \\
\hline Auxiliar de serviços gerais & Engenheiro de produção \\
\hline Analista de desenvolvimento de sistemas & Gerente de produção e operações florestais \\
\hline Administrador de sistemas operacionais & Supervisor da área florestal \\
\hline Auxiliar administrativo & $\begin{array}{c}\text { Operador de branqueador de pasta para fabricação de } \\
\text { papel }\end{array}$ \\
\hline $\begin{array}{l}\text { Eletricista de manutenção } \\
\text { eletroeletrônica }\end{array}$ & Técnico em maquinário florestal \\
\hline Técnico em informática & Técnico florestal \\
\hline
\end{tabular}

Fonte: Cadastro Geral de Empregados e Desempregados (2018), Programa de Disseminação das Estatísticas do Trabalho (2018) e Relação Anual de Informações Sociais (2018).

O quadro 3 apresenta dados coletados na Relação Anual de Indicadores Sociais (2018), no Cadastro Geral de Empregados e Desempregados (2018) e no (PDET) Programa de Disseminação das Estatísticas do Trabalho (2018), sobre as profissões mais exercidas, segundo as empresas de Imperatriz ou que atuam no município, entre 2008 e 2018. As 
Reestruturação Produtiva e Transformações no Emprego Industrial frente ao Avanço da Silvicultura...

ocupações estão sistematizadas em dois períodos (de 2008 a 2012 e de 2013 a 2018), representando os períodos anterior e posterior ao funcionamento da Suzano Papel e Celulose no município de Imperatriz.

No primeiro período (de 2008 a 2012), havia uma maior predominância de empregos voltados para o setor terciário. A partir de 2013, esse perfil passa por expressiva mudança: há um direcionamento para a busca de trabalhadores que atendam diretamente à cadeia produtiva de papel e celulose em suas mais diversas esferas, desde o plantio, corte e transporte do eucalipto até a produção da pasta de celulose e do papel propriamente dito.

Não há efetiva exclusão de empregos tradicionalmente responsáveis por importantes parcelas de contratação, uma vez que o setor de serviços ainda se constitui no maior empregador local. Contudo, como já destacado, há uma transição muito clara para o surgimento de empregos formais anteriormente inexistentes, como operador de calcinação, operador de máquina de fabricar papel e papelão, cilindreiro na preparação de pasta para fabricação de papel e operador de branqueador de pasta para fabricação de papel, todos voltados para as transformações em curso.

\section{CONSIDERAÇÕES FINAIS}

O avanço do processo de desenvolvimento capitalista, em especial nas atividades industriais atuais, torna constantemente necessário o sustento de uma forma crescente de acúmulo de capital, o que se dá em face do processo de concorrência cada vez mais acirrado nas economias de escala cada vez mais globalizadas. Tal concorrência cria ações coercitivas que forçam, nas formas de crises, a obrigatoriedade de construção e inserção de mecanismos maiores e mais constantes para a manutenção dos níveis de acúmulo de capitais e sobrevivência da fábrica. Tais particularidades, como já afirmam Harvey (2013) e Marx (1985), são inerentes à própria gênese do capitalismo.

Nos processos de reestruturação, o espaço como "lócus fundamental" do processo econômico e da própria sobrevivência concorrencial torna-se meio, mecanismo e fim na sustentação dos processos de reorganização produtiva em curso. Isso implica compreendermos que é nele que a atividade industrial do recorte aqui apresentada encontrará meios necessários para alterar e requalificar seus processos de produção.

Nesse contexto, a desterritorialização da produção, a utilização da terra e a requalificação profissional são instrumentos fundamentais na concorrência global e na acumulação. Em específico, a implantação da unidade fabril da Suzano Papel e Celulose no município de Imperatriz, localizado no sudoeste maranhense, possibilita-nos esse entendimento de modo claro e inequívoco. 
O avanço da silvicultura - base para o fornecimento de matéria-prima para da cadeia produtiva de papel e celulose - no sudoeste maranhense, trouxe consigo transformações não apenas na forma de exploração e reorganização do espaço local, como a construção de infraestrutura para a mobilidade do seu capital, ou nas formas de utilização da terra, mas, sobretudo, no reordenamento da força de trabalho local. Isso porque transportes, terra e trabalho são elementos centrais na reprodução do capital e na produção moderna da fábrica.

Se a terra barata encontrada no estado do Maranhão serve de base para o plantio florestal do eucalipto, os transportes permitem a mobilidade da matéria-prima e do produto final entre unidades de plantio, produção e exportação. No bojo do debate sobre geração de emprego e renda, ancorado expressivamente na estatal e agentes privados, a força de trabalho é redirecionada, requalificada e reordenada para servir como trabalho vivo ou massa de reserva qualificada para a atividade em curso. Os dados apesentados confirmam as considerações de Santos e Silveira (2001), que nos explicam que atores hegemônicos em curso, sobretudo em regiões periféricas, ao se instalarem e implantarem sua lógica tendem a atrair todas as multiplicidades espaciais para si; cria-se, assim, uma ordem para a empresa e um caos para os demais. Com a força de trabalho não seria diferente.

\section{REFERÊNCIAS}

ALVES, G. Trabalho e mundialização do capital: a nova degradação do trabalho na era da globalização. Londrina: Praxis, 1999.

CADASTRO GERAL DE EMPREGADOS E DESEMPREGADOS - CAGED. Participação de setores econômicos na geração de emprego no Brasil. Empregabilidade, profissões e perfis profissionais no emprego no Brasil em 2017. Disponível em:

https://caged.maisemprego.mte.gov.br/portalcaged/. Acesso em: 18 jun. 2018.

CANO, W. Raízes da concentração industrial em São Paulo. São Paulo: T. A. Queiroz, 1986.

CARLOS, A. F. Espaço e indústria. São Paulo: Contexto, 1992.

D'INCAO, M. A.; SILVEIRA, I. M. Amazônia e a crise de modernização. Belém: Museu

Paraense Emílio Goeldi, 1994.

HARVEY, D. Condição pós-moderna. São Paulo: Edições Loyola, 2008.

HARVEY, D. O enigma do capital e as crises do capitalismo. São Paulo: Boitempo, 2011. HARVEY, D. Os limites do capital. São Paulo: Boitempo, 2013.

IBGE. Produção extrativista e da silvicultura no Brasil, 2017. Disponível em:

https://www.ibge.gov.br/. Acesso em: 14 jul. 2018.

INDÚSTRIA BRASILEIRA DE ÁRVORES - IBÁ. Relatório de produção da silvicultura no

Brasil. São Paulo: IBÁ, 2017. Disponível em: https://www.iba.org/. Acesso em: 10 jul. 2018.

INSTITUTO NACIONAL DE ESTUDOS E PESQUISAS EDUCACIONAIS ANÍSIO TEIXEIRA - INEP. Educação Superior. Censo da educação superior: imperatriz, 2017. Disponível em: http://www.inep.gov.br. Acesso em: 24 set. 2018. 
Reestruturação Produtiva e Transformações no Emprego Industrial frente ao Avanço da Silvicultura...

LEÃO, R. M. A floresta e o homem. São Paulo: EDUSP/IPEF, 2000.

LEITE, E. M. Reestruturação industrial, cadeias produtivas e qualificação. In: CARLEIAL, L.; VALLE, R. (org.). Reestruturação produtiva e mercado de trabalho no Brasil. São Paulo: Hucitec, 1997. p. 140-168.

MARX, K. O capital. São Paulo: Civilização Brasileira, 1985.

MONTEBELLO, A. E. S. Configuração, reestruturação e mercado de trabalho do setor de celulose e papel no Brasil. 2010. Tese (Doutorado em Economia Aplicada) - Escola Superior de Agricultura Luiz de Queiróz, Universidade de São Paulo, Piracicaba, 2010.

OLIVEIRA, A. B. Implantação industrial, reestruturação produtiva e alterações no mercado de trabalho no sudoeste maranhense (2008-2018). In: SANTOS, L. C.; SEABRA, G. F.; CASTRO, C. E. (org.). Geografia: trabalho, sociedade e meio ambiente. São Luís: EDUEMA, 2018. p. 340-360.

OLIVEIRA, A. B.; PEREIRA, J. M.; NASCIMENTO, A. A. Cadeia produtiva de papel e celulose e transformações recentes no sudoeste maranhense. Revista Interespaço, Grajaú, MA, v. 4, n. 12, p.135-154, jan. 2018.

PANTOJA, V. M. L.; PEREIRA, J. M. Grandes projetos e populações tradicionais na Amazônia: a Suzano Papel e Celulose no Maranhão. Revista Política \&Trabalho, João Pessoa, n. 45, p. 327-340, jul./dez. 2016.

PROGRAMA DE DISSEMINAÇÃO DAS ESTATÍSTICAS DO TRABALHO - PDET. Estatística ocupacionais no Brasil, 2018. Disponível em: http://portal.mte.gov.br/portalmte/rais/. Acesso em: 29 jan. 2018.

RELAÇÃO ANUAL DE INFORMAÇÕES SOCIAIS - RAIS. Anuário Rais, 2008-2017. Brasília: Ministério do Trabalho, 2018. Disponível em: http://www.rais.gov.br/sitio/sobre.jsf. Acesso em: 22 abr. 2018.

SALM, C. et al. Produtividade na indústria brasileira: uma contribuição ao debate. In: CARLEAL, L.; VALLE, R. (org.). Reestruturação produtiva e mercado de trabalho no Brasil. São Paulo: Hucitec, 1997. p. 35-55.

SANT'ANA JÚNIOR, H. A. Projeto de cooperação internacional: projetos de desenvolvimento e populações locais: experiências em Cabo Verde e no Brasil. São Luís: Universidade Federal do Maranhão, 2014.

SANTOS, M. Espaço e método. São Paulo: EDUSP, 2008.

SANTOS, M.; SILVEIRA, M. L. O Brasil: território e sociedade no início do século XXI. Rio de Janeiro: Record, 2001.

SUZIGAN, W. Indústria brasileira: origem e desenvolvimento. São Paulo: Hucitec; Campinas: Unicamp, 2000.

Agradecimentos: À Fundação de Amparo à Pesquisa e ao Desenvolvimento Científico e Tecnológico do Maranhão - FAPEMA pelo auxílio financeiro concedido mediante o edital № 40/2015 UNIVERSAL para o projeto de pesquisa, "Localização industrial e (re)organização do espaço: análise da dinâmica de implantação da Suzano papel e celulose em Imperatriz MA" e edital № 002/2018 - UNIVERSAL para o projeto de pesquisa, "Especialização produtiva e uso competitivo do território no sudoeste maranhense pela cadeia de papel e celulose: técnica, terra e trabalho".

Recebido: outubro de 2018. Aceito: janeiro de 2019. 